\title{
En mann i 6o-årene med akutte ryggsmerter og økende kraftsvikt i underekstremitetene
}

NOE Å LÆRE AV

\section{GRO ØSTLI EILERTSEN}

E-post: gro.eilertsen@uit.no Institutt for klinisk medisin UiT - Norges arktiske universitet og

Revmatologisk avdeling Universitetssykehuset Nord-Norge og

Rehabiliteringssenteret Nord-Norges Kurbad

Gro Østli Eilertsen er ph.d., spesialist i revmatologi, førsteamanuensis og overlege. Forfatteren har fylt ut ICMJE-skjemaet og oppgir ingen interessekonflikter.

\section{NIKOLAOS PANAGIOTOPOULOS}

Avdeling for fysikalsk medisin og rehabilitering Universitetssykehuset Nord-Norge

Nikolaos Panagiotopoulos er spesialist i fysikalsk medisin og rehabilitering og overlege.

Forfatteren har fylt ut ICMJE-skjemaet og oppgir ingen interessekonflikter.

\section{TOR ARNØY AUSTAD}

Nevrokirurgisk avdeling

Oslo universitetssykehus, Ullevål sykehus

Tor Arnøy Austad er lege i spesialisering i nevrokirurgi.

Forfatteren har fylt ut ICMJE-skjemaet og oppgir ingen interessekonflikter.

\section{THOMAS GLOTT}

Avdeling for ryggmargsskade

Sunnaas sykehus

Thomas Glott er spesialist i fysikalsk medisin og rehabilitering og avdelingsoverlege.

Forfatteren har fylt ut ICMJE-skjemaet og oppgir ingen interessekonflikter.

En mann i 6o-årene fikk akutte ryggsmerter med utstråling til venstre lår. Helsepersonell mistenkte initialt venetrombose eller isjias. Fire timer etter smertedebut fikk pasienten nedsatt følelse og paralyse i begge underekstremitetene. Røde flagg i «Nasjonale kliniske retningslinjer for korsryggsmerter» omfatter ikke pasientens diagnose.

En yrkesaktiv mann i begynnelsen av 6o-årene fikk akutte korsryggsmerter med utstråling medialt og frontalt i venstre lår en morgen da han stod på badet og pusset tennene. Etter en time ringte han legevakten. Han nevnte at han tok 5,5 tabletter warfarin (Marevan) ukentlig 
grunnet tidligere lungeembolisme, og at han for en uke siden hadde startet med kandesartantabletter ( $8 \mathrm{mg}$ daglig) på grunn av hypertensjon. Sykepleieren på legevakten mistenkte venetrombose, og en paramedisiner ble sendt ut for tilsyn. Under unders $ø$ kelsen fikk pasienten akutt kraftsvikt i venstre ben. Paramedisineren fant ingen tegn til venetrombose og konkluderte med isjias. Han rådet pasienten til å hvile og se om smertene gikk over. Pasienten sovnet, og etter halvannen time våknet han med vedvarende ryggsmerter og kraftsvikt, men i tillegg var venstre ben helt følelsesløst. Han ringte AMKsentralen på nytt, men fikk beskjed om å vente, da det ikke var ledig ambulanse. En halvtime senere ringte pasienten nok en gang AMK-sentralen. Han hadde da fått nedsatt følelse og økende kraftsvikt i begge bena. Ambulansen kom cirka fire timer etter smertedebut.

Pasienten hadde ikke hatt ryggsmerter tidligere og kunne heller ikke relatere smertene til noen utløsende hendelse. Både sykepleieren på legevakten og paramedisineren, som undersøkte pasienten, mistenkte de mest opplagte diagnosene som venetrombose og isjias.

I likhet med internasjonale anbefalinger (1) deler «Nasjonale kliniske retningslinjer for korsryggsmerter» korsryggsmerter inn i tre kategorier som danner grunnlag for videre tiltak. Disse er: a) uspesifikke korsryggsmerter, b) nerverotsaffeksjon og c) mulig alvorlig underliggende spinal patologi eller cauda equina-syndrom, som f.eks. fraktur, tumor eller infeksjon. Sistnevnte kategori er merket med røde flagg (2). Røde flagg er varselfaktorer i sykehistorie og ved kliniske funn, og benyttes for å gjøre klinikere oppmerksomme på symptomer og tegn som kan ha betydning for oppfølging av den enkelte pasient med korsryggsmerter. «Pasient over 55 år som får ryggsmerter for første gang» og «konstante smerter, ev. tiltagende over tid, hvilesmerter» er eksempler på røde flagg og kunne hos vår pasient gitt indikasjon om behov for ekstra oppfølging (se ramme 1).

\section{Ramme 1 Varselfaktorer ved mulig alvorlig underliggende patologi (2). Røde}

\section{flagg.}

Ryggplager som debuterer, eller oppfattes annerledes enn tidligere plager, ved alder under 20 eller over 55 år

Konstante smerter, ev. tiltagende over tid, hvilesmerter

Generell sykdomsfølelse, feber og/eller vekttap

Traume, kreft, bruk av steroider eller immunsuppressiver, stoffmisbruk

Utbredte og eventuelle progrediserende nevrologiske utfall

Deformitet i ryggsøylen

Høy SR, uttalt morgenstivhet med varighet over en time

En halvtime etter siste kontakt med AMK-sentralen ankom pasienten akuttmottaket på et universitetssykehus. I journalopptaket ble pasientens sykehistorie kartlagt, og viktige opplysninger om årsaker til antikoagulasjonsbehandling kom frem. Ni år før den aktuelle hendelsen hadde pasienten hatt bilateral lungeembolisme og arteriell embolisme i høyre overarm. Grunnet truende iskemi var embolusen i overarmen blitt fjernet operativt, og pasienten behandlet med warfarin i noen måneder. To år etter operasjonen hadde han fått residiv av lungeembolisme, og var da blitt satt på livslang warfarinbehandling. Tre år før den aktuelle hendelsen hadde pasienten fått paroksysmalt atrieflimmer og var blitt behandlet med lungeveneisolasjon og isthmusblokk. Året etter hadde han fått residiv av atrieflimmer med påfølgende ny isolasjon av alle fire lungevener. INR-verdien hadde blitt regelmessig kontrollert og hadde vært stabil innenfor målområdet $(2,0-3,0)$. Ved den aktuelle innkomsten på universitetssykehuset hadde pasienten korsryggsmerter med VAS-skår (visuell analog skala) på 6 av 10, og smertene økte ved mobilisering. Han var kvalm, hadde urinretensjon og ingen kontroll av muskulatur rundt endetarmen. Undersøkelse av underekstremiteter viste paralyse for alle bevegelser fra hofteledd og 
distalt. Han hadde nedsatt sensibilitet for stikk og berøring i begge lår, mest uttalt i venstre lår, nedsatt temperatursans i hele venstre underekstremitet og fra kneet og distalt i høyre underekstremitet. Han hadde utslukket leddsans og bilateralt utslukket kne- og akillessenerefleks. Han skåret 2-3 på «Modified neuro-grade scale», (2 = para- eller tetraparese, 3 = para- eller tetraplegi) (3).

Tidsvinduet fra pasienten fikk akutte ryggsmerter med utstråling til han fikk symptomer på skade eller kompresjon av ryggmargen, med paraparese, utslukket kne- og akillessenereflekser, urinretensjon og slapp sfinktertonus, var 4,5 timer. Pasienten bodde i nærheten av universitetssykehus, og etter undersøkelsen i akuttmottaket ble han raskt overflyttet nevrokirurgisk avdeling for utredning og behandling.

Undersøkelser ved den aktuelle innleggelsen viste blodtrykk 146/68 mm Hg, puls 7o slag/min, Hb 15,4 g/dl (referanseområde 13,4-17,o g/dl), trombocytter $241 \cdot 10^{9} / \mathrm{l}\left(145^{-390}\right.$. $10^{9} / \mathrm{l}$ ), kreatinin $72 \mu \mathrm{mol} / \mathrm{l}(60-10572 \mu \mathrm{mol} / \mathrm{l})$ og hurtig-INR 2,6 (innenfor målområdet på 2-3). MR-undersøkelse viste intraspinalt subduralt hematom i nivå Th9-L1 med dislokasjon av ryggmargen og conus medullaris (figur 1). CT-angiografi viste ingen tegn til karmalformasjon eller arteriovenøs fistel. Etter tolkning av haste-MR fikk pasienten fytomenadion (Konakion, $10 \mathrm{mg}$ ) og protrombinkomplekskonsentrat (Octaplex, $2500 \mathrm{IE}$ ), dosert etter NevroNELs anbefalinger (4) for å unngå ytterligere blødning.

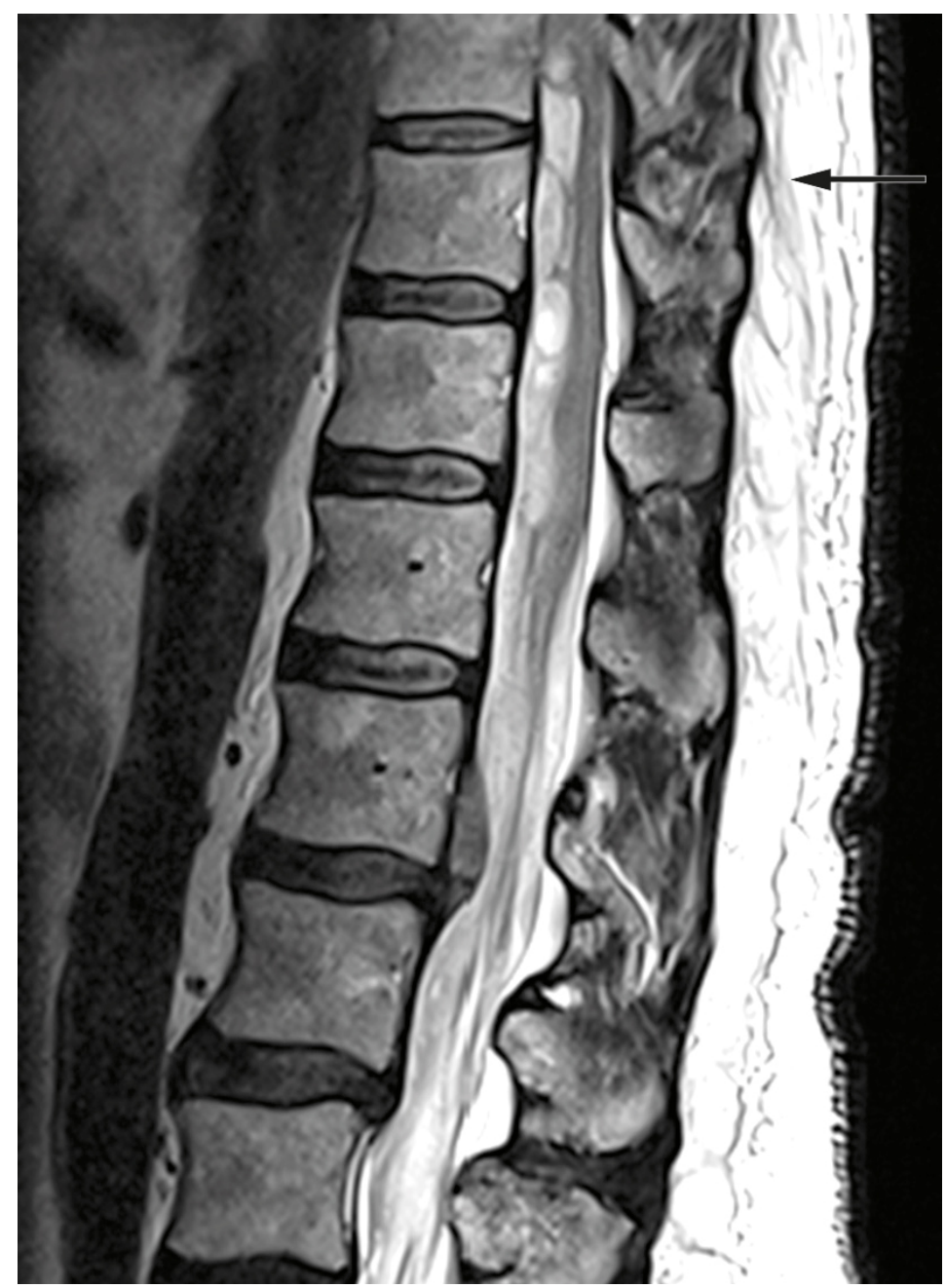

Figur 1 Preoperativ MR-undersøkelse: Intraspinalt subduralt hematom i nivå Th9-L1 og dislokasjon av ryggmarg og conus medullaris.

Antikoagulasjonsbehandling er den hyppigste årsaken til spinal blødning hos pasienter i alderen 46-75 år (5). Subduralt og epiduralt hematom er mest vanlig ved koagulasjonsbehandling (6). Ved innkomst var INR-verdien 2,6. Warfarin ble seponert, og pasienten fikk antidot etter ordinære retningslinjer.

Pasienten ble meldt til akutt operasjon i narkose. Det ble brukt kne- og albueleie, 
røntgengjennomlysning, midtlinjesnitt og laminektomi i tre nivåer. Peroperativt var det ikke noe epiduralt hematom, men blå, misfarget dura mater ble åpnet. Det ble skånsomt evakuert subduralt hematom, og det var ingen stor blødningskilde eller vansker med å oppnå hemostase. Ryggmargen var blålig misfarget, og en mistenkte betydelig blødning subaraknoidalt og intramedullært. Det ble da utført lukning under god hemostase. Postoperativ MR-undersøkelse viste volumredusert subduralt hematom i laminektomert nivå Th9-11, uendret subduralt hematom i nivå Th12, tilkomne intramedullære signalforandringer i nivå Th10-L1 og subaraknoidalt blod kaudalt for Th12 (figur 2).

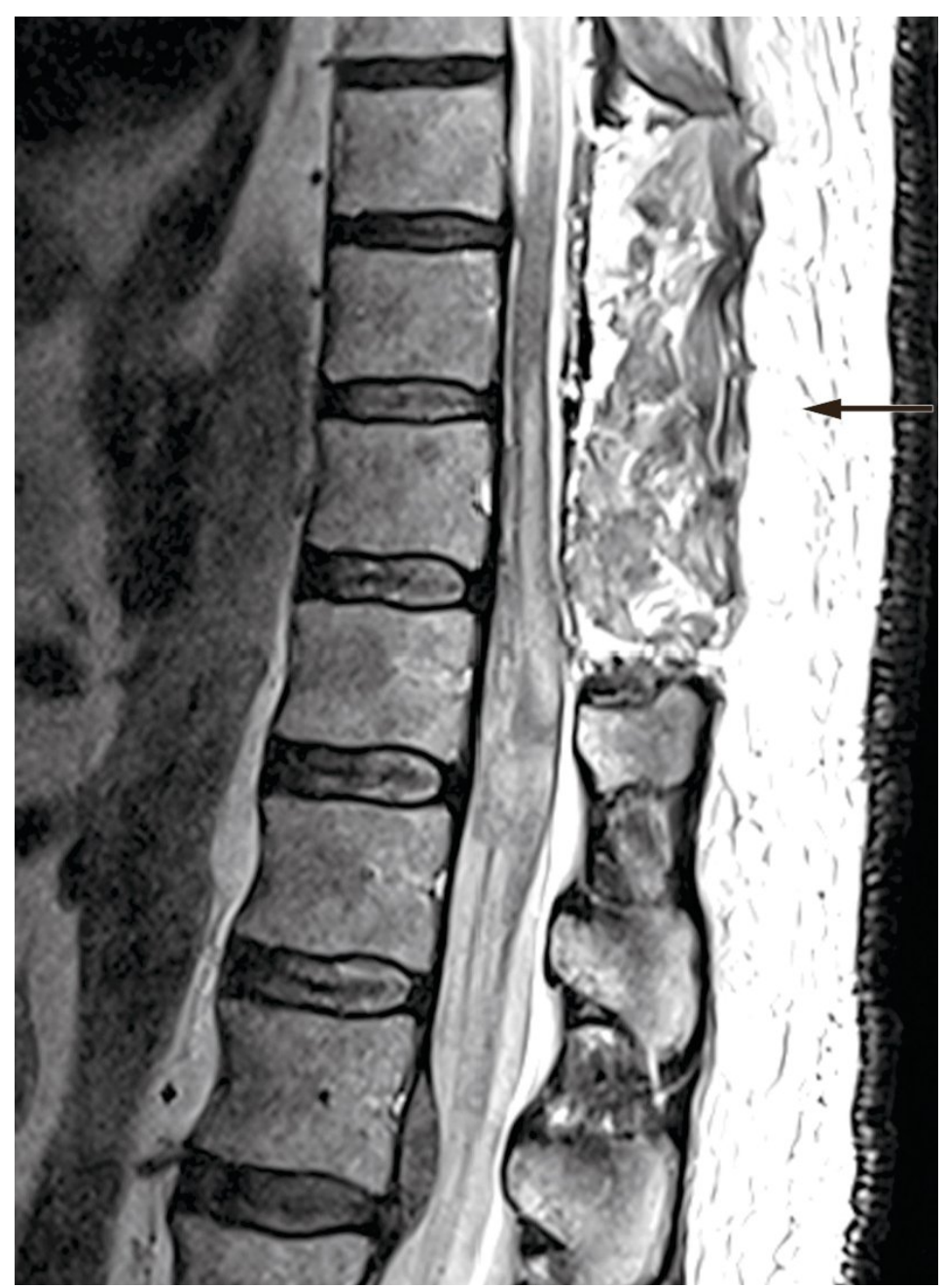

Figur 2 Postoperativ MR-undersøkelse: Utført laminektomi i nivå Thy-11. Volumredusert subduralt hematom $i$ operert nivå, uendret subduralt hematom $i$ Th12-nivå. Tilkommet intramedullcere signalforandringer i nivå Th1o-L1.

En tysk metaanalyse om spinale blødninger viser en klar sammenheng mellom tiden fra symptomdebut til kirurgisk behandling og tilbakegang av nevrologiske symptomer postoperativt. Ved operativ behandling innen tolv timer oppnådde $66 \%$ av pasientene komplett remisjon (5). Vår pasient ble operert elleve timer etter symptomdebut og hadde således antatt god prognose.

Pasienten hadde ingen bedring i nevrologisk status postoperativt. Det ble startet behandling med dalteparin (Fragmin, 5 ooo IE subkutant $\times 1$ ) første postoperative dag, og han ble rutinemessig behandlet på intensivavdeling med middelblodtrykk (mean arterial pressure, MAP) over $85 \mathrm{~mm} \mathrm{Hg}$ den første uken (7). MR-undersøkelse ble gjentatt etter ti dager og viste tilkommet epidural cerebrospinalvæskeansamling i nivå Th10-11 med kompresjon av ryggmargen (figur 3). På grunn av hodepine og kvalme supplerte man med MR av hodet. Denne viste litt intraventrikulært og subaraknoidalt blod, som ble tolket som distribuert fra den spinale blødningen. 


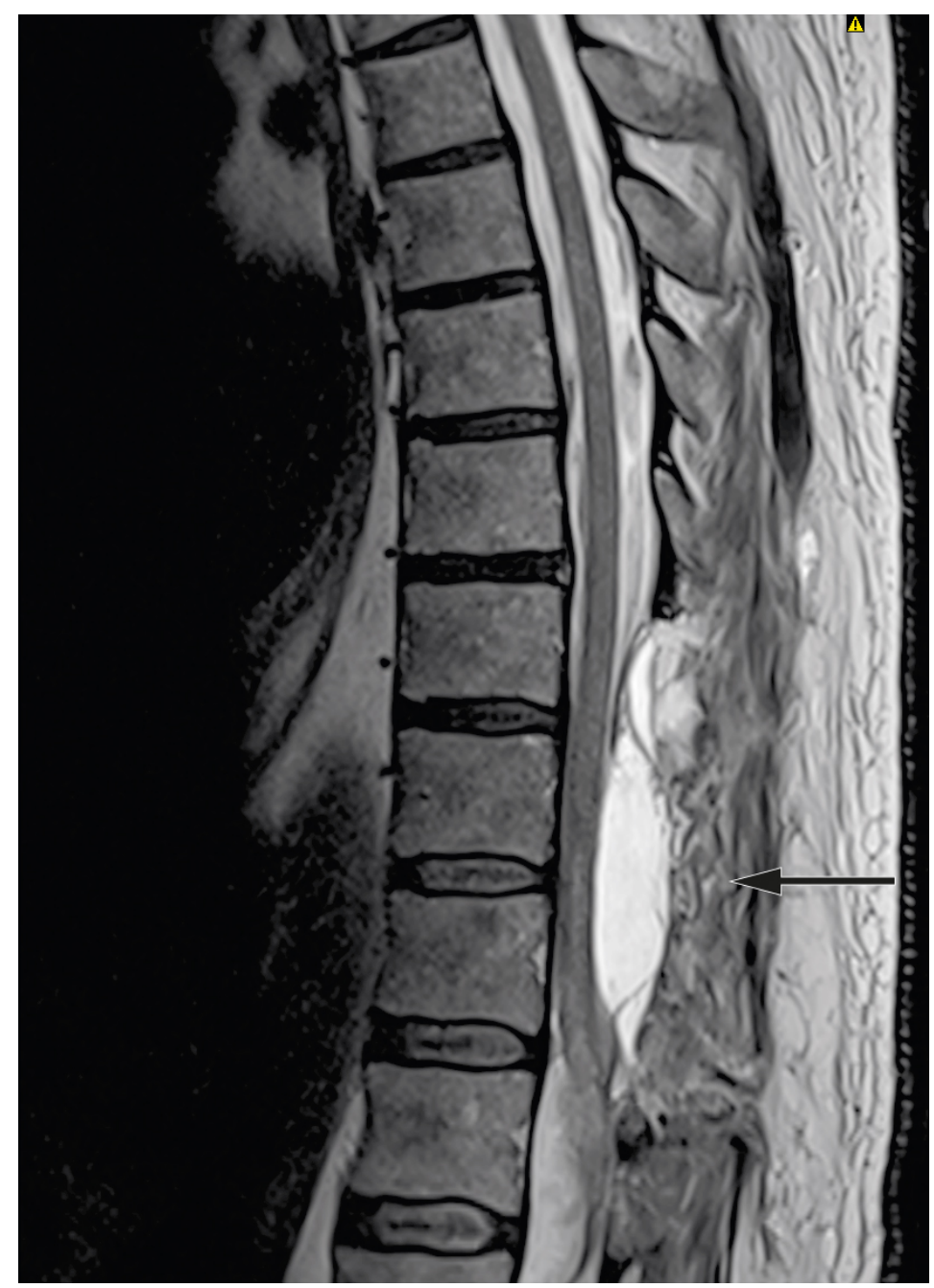

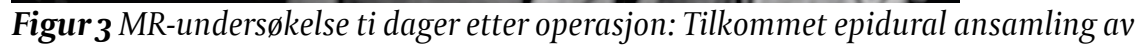
cerebrospinalvceske med masseeffekt.

Vedvarende nevrologiske utfall med paralyse og sensibilitetstap samt tap av kontroll over vannlatning og avføring tilsa behov for spesialisert rehabilitering. 18 dager etter sykdomsdebut ble pasienten overført til spinalenhet. Dalteparin ble da erstattet med rivaroksaban (Xarelto, $20 \mathrm{mg} \times 1$ ) grunnet tidligere lungeembolisme og atrieflimmer. Ved overflytning var begge ben paralytiske med redusert sensorikk fra nivå Th11. Reflekser var, som forventet i en spinal sjokkfase, utslukkede initialt. I en spinal sjokkfase vil det til tross for sentral skade foreligge slappe pareser og hyporefleksi de første fire-åtte ukene etter skade. Etter den spinale sjokkfasen kom reflekser tilbake med utvikling av spastiske pareser. Det var motorisk fremgang med 2-4-verdier i høyre ben og o-2-verdier i venstre ben etter internasjonale klassifikasjonskriterier (8). Sensorikk ble også gradvis bedret opp til nivå Th12. Under oppholdet hadde pasienten nevropatiske smerter, men han hadde ikke behov for medikamentell smertebehandling ved utskrivelse. Han hadde vedvarende nevrogen urinblære- og tarmdysfunksjon. Ved utskrivelse var det derfor behov for intermitterende selvkateterisering for tømming av urinblæren og laksantia for regulering av avføring til faste tider. Han trengte manuell rullestol til all forflytning, men var selvhjulpen i daglige gjøremål. Etter litt over tre måneders rehabilitering ble han utskrevet hjem til tilrettelagt bolig.

Pasienten ble på nytt henvist til universitetssykehuset da den kliniske fremgangen stagnerte fire måneder etter den aktuelle hendelsen. MR-undersøkelse av ryggsøylen viste da økt størrelse av cerebrospinalvæskelokulamentet i Th7-11 i tillegg til kjente signalforandringer i nedre ryggmarg og conus medullaris. Til tross for ny operasjon sju måneder etter hendelsen, med laminektomi i Th12 og fenestrasjon og tømming av araknoidal cyste i nivå Th11-12, oppnådde pasienten ingen klinisk bedring. Behandling med rivaroksaban ble gjeninnsatt postoperativt.

Fem måneder etter den aktuelle hendelsen fikk pasienten sitt første av til nå fem opphold 
på rehabiliteringssenter. Han har sekvele etter ryggmargsskade i nivå Th12, med redusert kraft, bevegelighet og funksjon i begge underekstremitetene, men mest uttalt på venstre side. Langsiktig rehabiliteringsmål var å gjenvinne gangfunksjon. Rehabiliteringen fokuserte på ståfunksjon ved trening i ståstativ, muskelstimulering i underekstremiteter med TEMS (transcutaneous electrical muscle stimulation) og øvelser for aktivisering av muskulatur og nervefunksjon i underekstremiteter. Treningen inkluderte sykling med assistert motorhjelp samt avlastende gangtrening på tredemølle med fasilitering av bekken og begge underekstremiteter. Pasienten har hatt fremgang i kraftutvikling, spesielt på høyre side, samt lett reduksjon i muskeltonus. Han bor nå alene i egen leilighet, bruker rullestol, kjører bil, gjennomfører egentrening to ganger per uke og får hjelp av en søster til vasking og handling. Han har normal avføring og utfører selvkateterisering, men har smerter og spasmer i bena som behandles med pregabalin (Lyrica), gabapentin (Neurontin) og baklofen (Baklofen).

\section{Diskusjon}

På lik linje med hjernen rammes ryggmargen av infarkt og blødninger, der cirka $15 \%$ er blødninger (6). Blødninger i ryggmargen er sjeldne, og insidensen er ukjent. Vi gjorde litteraturs $ø$ k i PubMed, men kunne ikke finne insidens for ryggmargsblødninger, kun for ryggmargsinfarkt, som er 3,1 per 100 ooo personår (9). Til sammenligning registrerte det nasjonale kvalitetsregisteret for ryggmargsskade i Norge 125 ryggmargsskader i 2018, hvorav $48 \%$ var ikke-traumatiske skader og $8,8 \%$ hadde vaskulær etiologi (10).

I likhet med i hjernen forekommer det også spontane blødninger i ryggmargen. En tredjedel er idiopatiske, men antikoagulasjonsbehandling, vaskulære malformasjoner og blødningssykdommer i ryggmargen er vanlige årsaker. Sammenheng mellom spinal blødning ved antikoagulasjonsbehandling med warfarin eller enoksaparin (Klexane) er kjent i litteraturen $(3,6)$. Arytmi og hypertensjon er predisponerende faktorer, og ved antikoagulasjonsbehandling i tillegg øker risikoen for spinal eller epidural blødning (5).

Vår pasient hadde flere risikofaktorer for spinal blødning: antikoagulasjonsbehandling, paroksysmal arytmi og hypertensjon. Noen land inkluderer blødningsrisiko i røde flagg ved ryggsmerter, f.eks. Canada, der koagulopati er et rødt flagg (11), men «Nasjonale kliniske retningslinjer for korsryggsmerter» verken inkluderer eller omtaler antikoagulasjonsbehandling ved ryggsmerter (2). Årsaken kan være at spinale blødninger er sjeldne, og at målgruppen for retningslinjene er tverrfaglig: leger, fysioterapeuter, kiropraktorer, osteopater, naprapater og sykepleiere.

Retningslinjer for røde flagg ved korsryggsmerter er konsensusbasert (1). Analyse viser at de fleste røde flagg har lav spesifisitet og lav sannsynlighetsratio for å oppdage alvorlig patologi, og at det er summen av flere røde flagg som bidrar til økt oppmerksomhet om mulig bakenforliggende sykdom (12). Da røde flagg ikke er forskningsbasert, er nytteverdien ved screening omdiskutert, og i en amerikansk oversiktsartikkel hevdes det at røde flagg ved ryggsmerter sannsynligvis er mer relatert til prognosen enn til oppdagelse av alvorlig underliggende patologi (13). Screening med røde flagg kan således gi falsk trygghet. Gullstandarden for å oppdage de sjeldne tilfellene med alvorlig patologi vil nok alltid være en god anamnese, målrettet klinisk undersøkelse, solid medisinsk kunnskap og ansvarlig oppfølging.

Antikoagulasjonsbehandling øker risiko for blødning, og med økende bruk av direktevirkende orale antikoagulanter (DOAK) kan dette bli utfordrende for klinikerne. På nåværende tidspunkt er det beskrevet kun fire kasuistikker med spinal blødning relatert til rivaroksaban og kun én kasuistikk med dabigatran (Pradaxa). Spinal blødning ved bruk av direktevirkende orale antikoagulanter involverer hovedsakelig cervikal- og torakalkolumna (80 \%), men dette er usikkert på grunn av få rapporterte tilfeller (14).

Vår pasient hadde klassiske symptomer på spinal blødning. Smertene var akutte og lokalisert til blødningsnivået i ryggmargen. I enkelte tilfeller etterfølges smertene av 
smertefrie intervaller. Deretter, avhengig av nivå på kompresjon av ryggmargen, utvikles kraftsvikt og sensorisk tap. En metaanalyse viste at i tillegg til akutte ryggsmerter hadde 30 \% fullstendig paralyse av tarm eller blæreforstyrrelser (5).

Beslutningen om hvorvidt man bør operere, tas av nevrokirurger, og er avhengig av etiologi og pasientens kliniske status. Blødning kan foreligge epiduralt, subduralt, subaraknoidalt eller intramedullært, og det kan være problematisk å se på MR-undersøkelse nøyaktig hvor blødningen ligger. Pasienter med epidural eller subdural blødning og nevrologiske utfall bør sterkt vurderes for akutt operativ behandling $(15,16)$. Ved spinale vaskulære lesjoner som blødningskilde kan intervensjonsradiologisk behandling vurderes i tillegg til kirurgisk behandling. For øvrig vil, i fravær av slike vaskulære lesjoner, vanlig kirurgisk strategi være adekvat dekompresjon og skånsom evakuering av hematom. Uavhengig av etiologi vil prognosen være uviss dersom det preoperativt foreligger alvorlige nevrologiske utfall.

Intraspinale blødninger med nevrologiske utfall og behov for rehabilitering inngår i kategorien ikke-traumatiske ryggmargsskader. Disse pasientene vil derfor være innen målgruppen for spinalenhetene i Norge, som er lokalisert ved St. Olavs hospital, Haukeland universitetssjukehus, Oslo universitetssykehus og Sunnaas sykehus. Kunnskapen om forløp og rehabilitering etter intraspinal blødning er sparsom, men enkelte kasuistikker og litteraturoversikter er publisert $(17,18)$. Forløpet til vår pasient er samsvarende med noen publiserte kasuistikker, der pasienter med intraspinale blødninger uten komplett bortfall av motorikk og sensorikk har delvis tilbakegang av nevrologiske utfall, og der et visst sekvele er vanlig. Etter spesialisert rehabilitering vil mange pasienter ha nytte av oppfølging i rehabiliteringsinstitusjon og primærhelsetjenesten.

Denne kasuistikken illustrerer at spinal blødning bør vurderes hos pasienter med antikoagulasjonsbehandling eller koagulopati og akutte nakke- eller ryggsmerter. Rask innleggelse ved nevrokirurgisk avdeling må etterstrebes fordi tiden med symptomer korrelerer med prognosen etter operasjon. Til tross for at antikoagulasjonsbehandling og koagulopatier øker risikoen for spinal blødning, er disse faktorene ikke inkludert i røde flagg i «Nasjonale kliniske retningslinjer for korsryggsmerter», noe som kan føre til at spinal blødning overses som årsak til ryggsmerter. Vi mener antikoagulasjonsbehandling bør inkluderes i røde flagg i «Nasjonale kliniske retningslinjer for korsryggsmerter». Dette kan enten gjøres ved å legge til «Koagulopati og bruk av antikoagulanter» som et eget punkt eller ved å inkludere dette i et eksisterende punkt: «Traume, svulst, bruk av antikoagulanter, steroider eller immunosuppressiva, stoffmisbruk».

\section{LITTERATUR:}

1. van Tulder M, Becker A, Bekkering JR et al. Chapter 3. European guidelines for the management of acute nonspecific low back pain in primary care. European spine journal 2006; 15:169-91. [CrossRef]

2. Nasjonale kliniske retningslinjer for korsryggsmerter - med og uten nerverotaffeksjon.

https://www.muskelskjeletthelse.no/wp-content/uploads/2016/o6/Nasjonale-kliniske-retningslinjer-k orsryggsmerter-2007-Fullversjon.pdf Lest 13.9.2019.

3. Domenicucci M, Mancarella C, Santoro G et al. Spinal epidural hematomas: personal experience and literature review of more than 1000 cases. J Neurosurg Spine 2017; 27: 198-208. [PubMed][CrossRef]

4. Veileder i akuttnevrologi. Oslo: Norsk Nevrologisk Forening, 2016. https://beta.legeforeningen.no/contentassets/5551044aa89f485eboec6geao7ce88o6/veileder-i-aku ttnevrologi-2016.pdf Lest 13.11.2019.

5. Kreppel D, Antoniadis G, Seeling W. Spinal hematoma: a literature survey with meta-analysis of 613 patients. Neurosurg Rev 2003; 26: 1-49. [PubMed][CrossRef]

6. Shaban A, Moritani T, Al Kasab S et al. Spinal cord hemorrhage. J Stroke Cerebrovasc Dis 2018; 27: 1435-46. [PubMed][CrossRef]

7. Saadeh YS, Smith BW, Joseph JR et al. The impact of blood pressure management after spinal cord 
injury: a systematic review of the literature. Neurosurg Focus 2017; 43: E20. [PubMed][CrossRef]

8. Kirshblum SC, Burns SP, Biering-Sorensen F et al. International standards for neurological classification of spinal cord injury (revised 2011). J Spinal Cord Med 2011;34: 535-46.

[PubMed][CrossRef]

9. Qureshi AI, Afzal MR, Suri MFK. A Population-Based Study of the Incidence of Acute Spinal Cord Infarction. J Vasc Interv Neurol 2017; 9: 44-8. [PubMed]

10. Halvorsen AP. NorSCIR Norsk ryggmargsskaderegister. Årsrapport 2018. Trondheim: St. Olavs hospital, 2019. https://stolav.no/Documents/2018\%20Årsrapport\%2oNorSCIR\%2oendeligdoc.pdf. Lest 18.11.2019.

11. Himmel W, Steinhart B, Helman A. Emergency Medicine Cases. Episode 26: Low Back Pain Emergencies. Podkast. https://emergencymedicinecases.com/episode-26-low-back-pain-emergencies/ Lest 13.11.2019.

12. Henschke N, Maher CG, Refshauge KM et al. Prevalence of and screening for serious spinal pathology in patients presenting to primary care settings with acute low back pain. Arthritis Rheum 2009; 60:3072-80. [PubMed][CrossRef]

13. Cook CE, George SZ, Reiman MP. Red flag screening for low back pain: nothing to see here, move along: a narrative review. Br J Sports Med 2018; 52: 493-6. [PubMed][CrossRef]

14. Ismail R, Zaghrini E, Hitti E. Spontaneous Spinal Epidural Hematoma in a Patient on Rivaroxaban: Case Report and Literature Review. J Emerg Med 2017; 53: 536-9. [PubMed][CrossRef]

15. Shin JJ, Kuh SU, Cho YE et al. Surgical management of spontaneous spinal epidural hematoma. Eur Spine J 2006; 15: 998-1004. [CrossRef]

16. Küker W, Thiex R, Friese S et al. Spinal subdural and epidural haematomas: diagnostic and therapeutic aspects in acute and subacute cases. Acta Neurochir (Wien) 2000; 142: 777-85. [PubMed][CrossRef]

17. Raasck K, Habis AA, Aoude A et al. Spontaneous spinal epidural hematoma management: a case series and literature review. Spinal Cord Ser Cases 2017;3: 16043. [PubMed][CrossRef]

18. Miller DR, Ray A, Hourihan MD. Spinal subdural haematoma: how relevant is the INR? Spinal Cord 2004; 42: 477-8o. [PubMed][CrossRef]

Publisert: 30. mars 2020. Tidsskr Nor Legeforen. DOI: 10.4045/tidsskr.19.0591

Mottatt 13.9.2019, første revisjon innsendt 25.11.2019, godkjent 27.1.2020.

(C) Tidsskrift for Den norske legeforening 2020. Lastet ned fra tidsskriftet.no 